\title{
Digital Sampling Rate
}

National Cancer Institute

\section{Source}

National Cancer Institute. Digital Sampling Rate. NCI Thesaurus. Code C142234.

The number of digital samples taken or recorded per unit of time. 